\title{
Phenomenal Intentionality and the Perception/Cognition Divide Uriah Kriegel
}

In A. Sullivan (ed.), Sensations, Thoughts, and Language: Essays in Honor of Brian Loar, Routledge

\begin{abstract}
One of Brian Loar's most central contributions to contemporary philosophy of mind is the notion of phenomenal intentionality: a kind of intentional directedness fully grounded in phenomenal character. Proponents of phenomenal intentionality typically also endorse the idea of cognitive phenomenology: a sui generis phenomenal character of cognitive states such as thoughts and judgments that grounds these states' intentional directedness. This combination creates a challenge, though: namely, how to account for the manifest phenomenological difference between perception and cognition. In this paper, I argue that there is in fact no obvious account of this difference. I consider three main approaches: in terms of high-level vs. low-level contents, of conceptual vs. nonconceptual content, and of propositional vs. objectual content. After arguing against each, I conclude by considering the phenomenal-intentionalist's options moving forward.
\end{abstract}

\section{Introduction: Phenomenal Intentionality and Cognitive Phenomenology}

There is a line of thought, at one time almost orthodox, that divides the mind-body problem into two parts: the problem of consciousness and the problem of intentionality. The problem of consciousness concerns how to fit into physical reality the phenomenal character of perceptual experiences, bodily sensations, and other paradigmatically phenomenal states. The problem of intentionality concerns how to fit into physical reality the intentional directedness of belief, desire, and other propositional attitudes - paradigmatically intentional states. 
Radical versions of this line of thought take phenomenal character and intentional directedness to have non-overlapping extensions: mental states divide into phenomenal and non-intentional states such as feeling ticklish and intentional but nonphenomenal states such as thinking that the weather is nice. This is what Horgan and Tienson (2002) have called "separatism. " 1 These specially radical versions go beyond the basic idea I want to focus on here, which may be formulated as follows: phenomenal character and intentional directedness are ontologically independent features. (This can be the case even if phenomenality and intentionality are perfectly coextensive.) What this means depends on one's approach to ontological (in)dependence. On a traditional modal approach, it means that for any determinate phenomenal character and intentional content, it is possible for a mental state to exhibit the former without the latter and vice versa. On the newfangled groundtheoretic approach, it means that intentional content is never exhibited by a mental state in virtue of that state's phenomenal character, and vice versa.

The mutual ontological independence of phenomenality and intentionality has recently come under attack from two directions. One view, often referred to "representationalism" (see Dretske 1995), holds that intentional content grounds phenomenal character; or perhaps more precisely, that there is a kind of intentional content such that phenomenal character is grounded in it. Another view, often referred to as the "phenomenal intentionality view" (see Loar 1987 for an early statement of the basic idea and Loar 2003 for the term "phenomenal intentionality"), holds that phenomenal character grounds intentional content; or perhaps more cautiously, that there is a kind of intentional content such that phenomenal character grounds it. The idea is that purely in virtue of its phenomenal character, and without need of interpretation, a perceptual experience as of a red square to the right and a blue circle to the left, say, has accuracy conditions, hence a kind of intentional content (Siewert 1998).

The core difference between representationalism and the phenomenal intentionality view (henceforth, PIV) pertains to the direction of grounding: representationalism holds that phenomenal character is had in virtue of (the right kind of) intentional content, PIV that (the right kind of) intentional content is had in virtue of phenomenal character. There is also a more ancillary difference, which does not quite fall out of these views but does seem to be a robust and natural accompaniment. This 
concerns the question of whether conscious thoughts, judgments, and other propositional attitudes exhibit a kind of sui generis phenomenal character that does not simply derive from the phenomenal character of inner speech, visual imagery, and the like sensory phenomena. At a purely sociological level, it seems that representationalists have not on the whole embraced this idea of a proprietary "cognitive phenomenology," whereas proponents of PIV almost universally have (Strawson 1994, 2011, Siewert 1998, 2011, Horgan and Tienson 2002, Pitt 2004, Bayne and Montague 2011, Chudnoff 2015, Kriegel 2015, Bourget 2017, Montague 2017). It is a fair question why this sociological alignment is so tight, but from a neutral standpoint, the following makes sense: if perceptual states' intentional content is not a primitive feature but is grounded in something, and cognitive states have a similar kind of intentional content, then we should expect the intentional content of cognitive states to be non-primitive as well, and indeed to be grounded in the same kind of thing the content of perceptual states is. So if one holds that the perceptual states' intentional content is grounded in their phenomenal character, one is naturally led to hold that the intentional content of (conscious) cognitive states is grounded in their own phenomenal character.

This combination does produce a special challenge, however: that of accounting for the evident difference between the phenomenal characters of conscious perception and cognition. For someone who holds that perceptual experiences are phenomenal but not intentional and cognitive states are intentional but not phenomenal, there is a simple and clear line of demarcation here. But for someone who holds that both perceptual experiences and conscious thoughts exhibit phenomenal intentionality, something else must be said to account for the manifest difference between the two. Perhaps the answer is that perceptual and cognitive states simply exhibit different kinds of phenomenal intentionality. But the question is how to give an informative account of the difference between the phenomenal intentionality characteristic of perceptual experience and the phenomenal intentionality characteristic of conscious thought.

Compare a perceptual experience of a brown dog and a conscious thought about a brown dog. (Note well: by "conscious thought" I mean not a visual image of a brown dog, but a properly intellectual state.) The untutored introspective impression is that there is a clear experiential difference between the two. Moreover, it seems that, at least in normal circumstances, we can easily tell whether our current brown-dog- 
representing conscious state is a perceptual experience or a thought. The natural explanation is that we do so by picking up on the phenomenal character of our browndog-representing conscious state - picking up, that is, on whether it is a perceptual or a cognitive phenomenal character.

At one level, the difference between perceptual and cognitive phenomenology is straightforward. The question is how to capture this difference in a literal and informative manner. We might say, for instance, that in perception objects are directly present to us, whereas in thought they are not; or that perception presents its objects, whereas thought merely re-presents them. Husserl seems to hit the nail on the head when he says that while perceptual experiences present their objects in the flesh ('in persona,' he writes), thoughts do not. But what do such formulations exactly mean? Our problem is how to get underneath such suggestive expressions and provide a substantive, informative account of the difference between the phenomenal intentionality of perception and that of thought. Given that the difference between perception and thought is such a bright a line within the field of conscious phenomena, addressing this challenge ought to be one of the central items on the agenda of the phenomenal intentionality research program.

In the 1970s and 80s, many sophisticated accounts of the perception/cognition divide were offered by philosophers and psychologists. But these tended to draw the distinction in terms of subpersonal or architectural features that do not seem phenomenally manifest - whereas what PIV needs is precisely a phenomenally manifest difference between the two. Consider the notion that perceptual processes are 'modular' whereas cognitive ones are 'central.' Fodor (1983) adduced nine features distinguishing modular from central states, most prominently domain-specificity, informational encapsulation, and fixed neural implementation. However, Fodor did not intend any of these to be in any way associated with phenomenal character, and they certainly do not seem to be. But for the phenomenal intentionality fan who accepts cognitive phenomenology, there should also be a purely phenomenal, first-personally appreciable difference between the two. This first-personally appreciable difference could - indeed, probably is - grounded in some difference at the level of subpersonal mechanism; but the question before us concerns the nature of the phenomenal difference thus grounded, not the nature of the underlying mechanistic difference. Thus our question can be seen as transforming the old problem of drawing the 
perception/cognition divide from a problem about kinds of subpersonal architecture to a problem about kinds of phenomenal intentionality.

What I will argue is that there is in fact no easy way to do this. I will consider three main types of approach (each branching into a number of subtypes): that the key difference is between perception's low-level contents and thought's high-level contents (§2); that it is the difference between nonconceptual and conceptual content (§3); that it is the difference between an 'objectual' and a propositional content (§4). I will conclude that none of these works, and will consider PIV's options for where to go from there $(\S 5)$.

Before starting, two housekeeping comments. First, I will use the expressions 'cognition' and 'thought' interchangeably, and have in mind the exercise of the characteristically intellectual capacities involved in conceptual thought, judgment, reflection, and so on. There is a use of the term 'cognition' that makes it considerably wider, covering mental imagery, episodic memory, and any other stimulusindependent mental phenomena (see Phillips forthcoming). There is even a use of 'cognitive' where it means essentially the same as 'mental' (see under: 'cognitive science'). I will not be using the term 'cognitive' in these more extended senses, because that is not the sense relevant to the phenomenology of thought, judgment, and other cognitive states. Secondly, I will use the locution 'thinking about' to cover both thinking-that and thinking-of. The locution 'thinking that' tends to figure in reports of mental states that take a stand on the truth of that-which-is-thought, such as judgment, belief, and perhaps acceptance. In contrast, the locution 'thinking of' tends to figure instead in reports of mental states that do not take a stand on the question of truth, such as considering, entertaining, or contemplating something. Since the difference between the two will not matter to us here, I will usually use the locution 'thinking about,' which seems to me neutral between the two. ${ }^{2}$

\section{Low-Level vs. High-Level Contents}

A straightforward approach to the difference between the phenomenal intentionalities of perception and thought is to claim that perception and thought simply represent 
different things. In particular, it might be suggested, perception represents low-level properties, such as color and shape, whereas thought represents high-level properties, such as being a Labrador and being illegal.

Setting aside debates over whether perception might represent some high-level properties as well (Siegel 2010), the main problem here is that thought can clearly represent low-level properties. You can see red, but you can also think about red; you can smell the odor of freshly ground coffee, but you can also think about it. Again, by this I mean not just that you can imagine that color and that odor. I mean that you can also form judgments about them. Indeed, it is commonly thought that one way we can form judgments or beliefs is simply by endorsing our perceptual experiences. If I seem to see that there is a red triangle in front of me, and take at face value my visual experience - i.e., endorse it - I thereby form a judgment that there is a red triangle in front of me. The result is a cognitive state that represents the same low-level properties that the visual experience did.

It is true, of course, that there is still this general difference between thought and perception: thought can represent some properties that perception cannot. It is possible to think that virtue is its own reward, but impossible to smell or see anything of the sort. However, this does not help us to distinguish a dated token perceptual experience of a red triangle from a dated token thought about a red triangle. It may help us distinguish the faculties of perception and thought (if there are such things), or the natural kinds Perceptions and Thoughts (ditto). But given an individual perceptual experience of some sensible entity and an individual thought formed by mere endorsement of that perceptual experience, the two will represent the same (low-level) properties. $^{3}$

Might someone insist that, in fact, the redness-related properties represented in perception and in thought are not exactly the same? This is certainly a coherent option. Perhaps the claim could be that perception represents apparent redness (understood as a property of external objects - see Shoemaker 1994, Egan 2006), whereas thought represents real redness. One problem with this strategy is that we are left with no obvious way to account for the apparent possibility of forming thoughts via endorsement, since the properties represented by color perceptions and color thoughts are systematically different. But more deeply, it is unclear what prevents me 
from thinking about whatever feature I am currently visually aware of - if only under that description.

This suggests that the real issue here cannot be what property is being represented, but how it is represented. Thus, just as one may have two concepts for Venus, a Phosphorescent concept and a Hesperescent concept, one may also have two concepts of red, a perceptual concept and a cognitive concept. It might be suggested, then, that a perceptual experience of a red triangle deploys perceptual concepts of redness and triangularity, while a conscious thought about a red triangle deploys cognitive concepts of redness and triangularity.

Put this way, the account is not particularly illuminating. All it does is pass the buck from the difference between perceptual and cognitive states to the difference between perceptual and cognitive concepts. This does not quite advance our understanding of the essential difference between the perceptual and the cognitive; it only shifts the locus of the distinction from the realm of states to that of concepts.

The phenomenal intentionalist may, of course, attempt to offer a more informative account of the distinction between perceptual and cognitive concepts. However, it is important to stress that such an account could not appeal to subpersonal or unconscious phenomena that are not manifest in the phenomenology. For what we are trying to account for is the difference between perceptual and cognitive phenomenology. Thus an account in terms of difference between the functional or inferential roles of perceptual and cognitive concepts would be problematic: on the face of it, functional/inferential role is a dispositional property, whereas phenomenal character is occurrent.

Furthermore, whatever account of the difference between perceptual and cognitive concepts the phenomenal intentionalist offers, the notion that this is what explains the phenomenal difference between perception and thought has the unfortunate consequence that thoughts can never be formed by endorsement, that is, by taking at face value certain perceptual experiences. Suppose you see a red triangle before you, and then think that there is a red triangle before you. Your perception will have a content $\mathrm{C}$, featuring as constituent the perceptual concept of red, whereas your thought will have a different content $C^{*}$, featuring as constituent a cognitive concept of 
red. Thus the formation of thoughts by simple endorsement of perceptual experiences becomes mysterious.

For all these reasons, it seems unlikely that the phenomenal difference between perception and thought comes down to the difference between representing low-level vs. high-level properties, or to the difference between low-level vs. high-level concepts used to represent properties.

The phenomenal intentionalist might then suggest that the difference between a perceptual way and a cognitive way of representing red goes deeper than the use of different concepts. In fact, she might suggest, the perceptual way represents without the use of concepts at all, whereas the cognitive way is conceptual. Let us consider this approach next.

\section{Nonconceptual vs. Conceptual Content}

The notion that perception has nonconceptual content whereas thought has conceptual content is widely held among representationalists (Dretske 1995, Tye 1995). There is no reason why PIV cannot avail itself of the same idea. On this view, a perception and a thought may both represent red, but the cognitive representation deploys the concept RED, whereas the perceptual representation does not.

One immediate issue in evaluating this suggestion is the absence of any consensus on what the conceptual/nonconceptual distinction exactly amounts to. The variety of theories in this area is bewildering, but broadly speaking, there are two general ways to construe the conceptual/nonconceptual distinction (Heck 2000). On the content-based distinction, a conceptual representation of a brown dog has a content of which both the concept BROWN and the concept DOG are constituents; a nonconceptual representation of a brown dog has a categorically distinct kind of content, one that does not have concepts for constituents (more on this in §3.2). On the state-based distinction, a conceptual representation of a brown dog is a representational state a subject cannot be in unless she possesses the concepts BROWN and DOG; a nonconceptual representation is a representational state the subject can be in even if she does not possess BROWN and DOG. 
It is commonly agreed (see Byrne 2005, Speaks 2005, Heck 2007) that in relevant discussions, the state-based distinction has been more central. Accordingly, I start by considering using that distinction to capture the phenomenal difference between perception and thought (\$3.1); then I consider using the content-based distinction (§3.2).

\subsection{Perception, Cognition, and the state-based conception of (non)concceptuality}

If we use the state-based distinction, the suggestion becomes effectively this: a perceptual experience of a brown dog is a phenomenal-intentional state we can be in even if we do not possess the concepts BROWN and DOG; an occurrent thought about a brown dog is a phenomenal-intentional state we cannot be in unless we possess BROWN and DOG. Certainly among representationalists this seems to me the most common approach to the difference between conscious perception on the one hand and cognition on the other; this is explicit in Tye's (1995) PANIC theory, and implicit in Dretske's (1981) notion that perception employs an analog format whereas thought employs a digital format. The idea is that perception presents us what it does in a much finer-grained fashion than thought does, as our capacities for perceptual discrimination typically far outstrip the concepts we possess, so our perceptual awareness can capture details that thought cannot.

This approach seems initially promising, by my view is that its allure is due to purely contingent facts about human perception and thought that shed no light on the deep natures of perception and thought. To show this, let me present a two-step objection.

The first step is to note that failure to possess a concept for feature $F$ is not a necessary condition for having a perceptual experience of $F$. Imagine a creature whose visual field is a perfect square (say, because of the peculiar shape of its visual organs) and who has a visual experience of a pure white Ganzfeld. The only features she is visually experiencing are thus the color white and perhaps the shape square - two features for which most of us, and, let us stipulate, this creature, do possess the concepts. It would be odd to suppose that as soon as this creature acquires the 
concepts WHITE and SQUARE, she loses the ability to have a visual experience when standing in front of a uniformly white wall.

Indeed, we can also conceive of a supersentient creature who, amazingly, possesses a concept for every shade of red and every polygon up to the megagon (the million-sided polygon). Call this creature Lynceus (after the Greek god of whom he reminds). Lynceus can discriminate red $_{273}$ from red red4, $_{\text {, }}$ recognize a sample as red $\mathrm{d}_{273} \mathrm{a}$ year after first seeing it, and draw appropriate inferences about red $\mathrm{d}_{273}$ objects. Some philosophers hold that such capacities are constitutive of possessing the concept RED 273, others that they are merely evidence of possessing it; I do not take a stand on this here, but I stipulate that Lynceus possesses both the capacities and the concept. Imagine now that Lynceus is presented with a red 273 chiliagon. It would be perverse to say that Lynceus cannot perceptually experience the red $_{273}$ chiliagon (can only think about it) because of his increased perceptual acuity and processing power. From this perspective, it seems to be a merely contingent fact about us that we fail to possess concepts for some features we can perceive; it is not in the nature of perception to outstrip the perceiving subject's conceptual repertoire.

There is an objection to this reasoning, which invites the promised second step. The objection is that the state-based conception of non-conceptuality does not require a perceptual experience to outstrip our conceptual repertoire; all it says is that a nonconceptual state is one that the subject can be in even if she does not possess the relevant concepts. And although Lynceus possesses the concepts CHILIAGON and RED 273, the perceptual state he is in when presented with a red ${ }_{273}$ chiliagon is one he could be in even if he failed to possess those concepts. That is, although in the world we just envisaged Lynceus possesses both CHILIAGON and RED 273 , there is another world W where (i) Lynceus does not possess the concepts CHILIAGON and RED 273 , but (ii) Lynceus is in the same mental state. ${ }^{4}$

The second step of the problem starts from granting that there is a world like W. But its existence raises the following question: What makes it the case that Lynceus' mental state in W is the same as (type-identical to) the state in which he is in the world we originally envisaged (the world where he does possess CHILIAGON and RED 273 )? In particular, what makes it the case that in both worlds it is a perceptual state - as opposed to being a perceptual state in $\mathrm{W}$ and a cognitive state in the originally 
envisaged world? If Lynceus' state is perceptual even in the world in which Lynceus possesses the concepts CHILIAGON and RED 273, what makes it the case that it is perceptual? However one answers this question, the answer will effectively preempt nonconceptuality as the criterion for perceptuality. In other words, the assumption that Lynceus can have perceptual experiences of $F$ both in worlds where he possesses the concept of $\mathrm{F}$ and in worlds where he does not presupposes that there is some feature, more basic than concept-possession, that accounts for the perceptuality of a conscious state.

For example, suppose one said this: the reason Lynceus' state is the same in (type-identical across) both worlds, and therefore is a perceptual state even in the world where Lynceus possesses the concepts CHILIAGON and RED 273 , is that in both worlds it represents low-level properties (colors and shapes). Then one's defense of the conceptual/nonconceptual account of the difference between perception and thought presupposes the low-level/high-level account. The latter is in a sense one's real account. Now, the fact that we have already argued against the low-level/high-level account is not what matters to me here. What matters is the fact that the conceptual/nonconceptual account cannot stand on its own, given the possibility of creatures like Lynceus. It must rely on a more fundamental account. ${ }^{5}$

The upshot is that once we admit that a mental representation of $\mathrm{F}$ can be perceptual despite the subject possessing the concept of $F$, there must be some deeper reason for its status as perceptual (as opposed to cognitive) than nonconceptuality understood in the state-based way. The difference between the conceptual and the nonconceptual can no longer be the ultimate difference between perception and cognition.

\subsection{Perception, Cognition, and the content-based conception of (non)concceptuality}

The content-based distinction between conceptual and nonconceptual content generates the following view: a conscious thought that the dog is brown has for content a structured proposition whose constituents include the concepts DOG and BROWN; a perceptual experience of the dog being brown has for content a categorically different kind of entity. What categorically different entity? Well, there are three 
importantly different alternatives to a structured proposition whose constituents are concepts: (a) a structured proposition whose constituents are not concepts; (b) an unstructured proposition; (c) an entity other than a proposition. Each may be plugged into a content-based attempt to capture the phenomenal difference between perception and thought in terms of (non)conceptuality.

Option (a) holds that while the conscious thought that the dog is brown has for content the structured proposition whose constituents include DOG and BROWN, the corresponding perceptual experience has for content a similar structure, but featuring as constituents not the concepts DOG and BROWN, but some nonconceptual analogs thereof - perhaps the nonconceptual modes of presentation $\mathcal{D O G}$ and $\mathcal{B R O W N}$.

An immediate worry here is that it is far from clear what modes of presentation exactly are. If they are constituents of proposition-like structures, and these structures are abstract entities, then presumably they are themselves abstract entities, though not quite the same abstract entities that concepts are. But we really know next to nothing else about the kind of things they are.

More worryingly, from our perspective, the difference between the abstract structures $\angle$ BROWN + DOG $>$ and $\angle \mathcal{B R O W N}+$ DOG $>$ does not seem to be of the right kind to capture the phenomenal difference between perception and thought. ${ }^{6}$ For it is hard to see how the difference between those two structures could deliver the difference between presentation of a brown dog in the flesh and presentation of the same dog not in the flesh. What is it about the abstract structure $\langle\mathcal{B R O W N}+\mathcal{D O G}\rangle$ that makes the dog present to us in the flesh? Just invoking that abstract structure and distinguishing it from the conceptual abstract structure $\angle B R O W N+$ DOG $>$ does not get us any closer to answering that question. We can, of course, simply use the expression 'nonconceptual mode of presentation' as a label for presentation-in-the-flesh. But if this is all we are doing, we are offering nothing that gets underneath the observation that perceptual experiences have the kind of content that presents in the flesh while conscious thoughts have the kind of content that does not. We are renaming the explanandum, not explaining it.

Alternative (b) is worse still. The idea here is that when we speak of the proposition <the dog is brown>, there are really two distinct entities we may be 
referring to: (i) a structured proposition with conceptual constituents and (ii) an unstructured proposition. Perceptual experience of the dog being brown carries (ii), conscious thinking about the dog being brown carries (i). I should stress that nobody in the literature has ever proposed this; I am considering this possibility merely for the sake of exhaustiveness.

The view obviously indulges an extravagant ontology of propositions. We need not endorse a general principle of 'explanatory closure of the concrete realm' (Kriegel 2011) to feel uncomfortable about positing all those different denizens of the Platonic heaven just to account for the concrete phenomenal difference between seeing a brown dog and thinking about a brown dog. Furthermore, it is hard to see how this view accommodates the idea that we can form a thought simply by endorsing a perceptual experience. The view requires endorsement to be a special procedure that transubstantiates unstructured propositions into structured ones. In addition, the distinction between structured and unstructured propositions seems no more fitted to capture the difference between a phenomenology of presenting-in-the-flesh and a phenomenology of presenting-not-in-the-flesh than the distinction between propositions composed of concepts and propositional structures composed of nonconceptual modes of presentation. These distinctions just do not seem to have the right shape to capture the distinctively in-the-flesh character of perceptual presentation.

To my mind, alternative (c) is the most promising. Here the idea is that while the thought content $<$ the dog is brown $>$ features a constituent structure with concepts as building blocks, perceptual content does not consist in the proposition $<$ the dog is brown> at all, nor any other proposition, conceived of either as unstructured or as structured out of nonconceptual ingredients. Instead it involves a non-propositional content.

What exactly is non-propositional content? The natural thought is that perceptual experience has objectual content, somewhat as love and fear are often claimed to do (Forbes 2000, Montague 2007). Intuitively, loving one's child is irreducible to loving that $p$ for any $p$. And likewise, one might plausibly suspect, seeing a brown dog is irreducible to seeing that $p$ for any $p$. Using chevrons to designate contents, whether propositional or not, we might say that while the thought has 
content of the form <the dog is brown>, the corresponding perceptual experience has content of the irreducibly objectual form <brown dog $>$. We consider this option next.

\section{Objectual vs. Propositional Content}

In truth, the propositional/objectual distinction can be interpreted either as a distinction concerning what is represented or as a distinction concerning how what is represented is represented. However, the former leads to an implausible account of the perception/cognition divide. It leads to the notion that while perceptions represent objects, thoughts represent propositions. Now, if the idea is that thoughts represent Russellian propositions - essentially, states of affairs - then it is not clear why perception should be incapable of doing the same. Looking at a red rectangle, I see not only the rectangle but also its redness. What I cannot see are rather Fregean propositions, understood as non-spatial, abstract structured entities inhabiting 'the third realm.' These are plausibly invisible, and more generally imperceptible. However, Fregean propositions make equally poor candidates for what thoughts represents - for that-which-thoughts-are-about. When I think that Max is a Labrador, that which I am thinking about is the specific dog Max and the kind of dog he is, not some shapeless and colorless counterpart of Max in the 'third realm.' The point becomes even more salient when we consider other propositional attitudes, such as desire. When you desire that your mother be happy, what you desire involves your actual mother; the fate of some corresponding abstractum is none of your concern. This is not to say that Fregean propositions have no role to play in the theory of propositional attitudes, including thoughts. Hesperus/Phosphorus phenomena suggest that they rather do. But the relevant role is not that of capturing that-which-is-thought-about.

The other interpretation of the propositional/objectual distinction allows that a perceptual experience and a thought may represent the same state of affairs - say, some rectangle's being red - but represent it differently. In particular, the thought involves a propositionally structured way of representing that state of affairs, whereby the redness is predicated of the rectangle, whereas the perception represents the state of affairs in a pre-predicative way, as an unstructured whole so to speak. We might write: the thought represents the rectangle's being red, whereas the perceptual 
experience represents the rectangle's-being-red (where the hyphens signal that 'red' is a not a syntactic, but only a morphological, part of 'rectangle's-being-red').

In this form, this seems to me the most promising of the PIV approaches we have discussed. It is a natural thought that what distinguishes merely sentient creatures from sapient ones is the latter's ability to 'put together' ideas (the intellect's 'power of synthesis') in the way characteristic of predication. Nonetheless, several considerations should worry us about the view's ultimate plausibility. I will present these as a series of queries to the view's proponent. I do not rule out that a satisfactory answer could be given to all of them, but going through them will bring out the tall order facing the view.

First of all: Is it so obvious that no perception has predicative content? Folk psychology certainly makes allowances not only for objectual perceptual reports, such as 'He sees a brown table,' but also propositional perceptual reports, such as 'She sees that the table is brown' ('She hears that the mailman has arrived,' 'She smells that the coffee is ready,' etc.). The latter ostensibly report predicative states. It might be retorted that the mental states reported in such constructions can be neatly factorized into two components, a purely perceptual one that is pre-predicative and a fully cognitive one that is predicative. But showing that this is so is very hard. The challenge is put very clearly by Søren Klausen:

Seeing that the rose is red is quite different from simultaneously seeing a red rose and thinking that a rose is red... [If perceiving-that] consisted of two distinct intentional states, there could be a genuine question about whether one was in fact thinking of the rose which one also happened to see. (Klausen 2008: 453)

When you perceive that the table is brown, there seem to be no possible daylight between the table you perceive and the table of which brownness is predicated. But such daylight would be possible if the factorizing strategy were correct.

Secondly, there is a converse question, albeit perhaps less pressing: Might there not be objectual cognitive attitudes? Folk psychology does make use of belief-in reports, wherein the psychological verb takes an objectual complement (as in 'Junior believes in Santa Claus'). Now, the obvious response here is that 'belief-in' reports are at bottom just lackadaisical ways of reporting existential beliefs-that: when we say that 
$\mathrm{S}$ believes in ghosts, all we mean is that $\mathrm{S}$ believes that there are ghosts. Nonetheless, some philosophers have explicitly argued against this analysis, claiming that at least some belief-in reports resist paraphrase into belief-that reports (Szabó 2003, Textor 2007, as well as Brentano 1874).

Third: Is the difference between a structured and an unstructured representation of a state of affairs a phenomenally manifest difference? A phenomenal difference is one that we might reasonably expect to be able to pick up on by the use of introspection, at least in favorable circumstances and given the right 'phenomenal contrasts.' If, using the right phenomenal contrasts and being sufficiently attentive, we could pick up on a subtle but phenomenally real act of predication that is built into our thoughts but is absent from our perceptual experiences, that would constitute important evidence for the account under consideration. But to my knowledge, no such evidence has been provided to date.

Fourth: Granting that perceptual phenomenology lacks a predicative dimension presenting in cognitive phenomenology, could this difference really exhaust the difference between the two types of phenomenology? A reason for skepticism is that that would again constitute a merely negative characterization of perceptual phenomenology. When a naïve subject 'tells' introspectively that she is having a perceptual experience of a brown dog, rather than a thought about a brown dog, she seems to pick up on something positive that is present in her conscious state, not just on some absence.

Finally, and relatedly: Is the difference between predicative and pre-predicative content the right kind of difference to capture the phenomenal difference between thought and perception? It is unclear why and how the absence of a predicative structuring of one's representation of something would 'spark into life' all those colors and sounds, nor why the presence of such predicative structuring make them fade away. It is hard to see the connection between the distinctive in-the-flesh character of perceptual awareness and predication.

\section{Conclusion: Where Do We Go from Here?}


If none of the aforementioned accounts of the phenomenally manifest difference between perception and thought is satisfactory, what are our options?

The most optimistic option is to hope that some other PIV account will be more successful than those we have considered here. Obviously, I have not considered every possible PIV account, and one of them might just work. This is of course possible, but would have to be shown.

Another option is to go primitivist. The idea is that there is a difference between perceptual phenomenal-intentional content and cognitive phenomenal-intentional content, but there is no way to get underneath that difference. We can use various metaphors, such as 'presenting in the flesh,' to make the difference vivid, but we cannot hope to offer any substantive account of the difference. Such primitivist moves are of course always available, and sometimes they are true; but always they are less theoretically satisfying than substantive accounts.

A more desperate option is to deny the datum. This could take the form of either (a) denying that there is a difference between perceptual phenomenology and cognitive phenomenology or (b) denying that there is a proprietary cognitive phenomenology to begin with. That is, even if perceptual experience has phenomenal intentionality, thought does not. Personally, both options strike me as frankly unbelievable, though I am aware that I have provided no argument against them.

A different way forward is to drop the claim that there is a difference between perception and thought at the level of phenomenal-intentional content, but insist that there is still a phenomenal-intentional difference, namely at the level of attitude or mode. The idea is to posit a cognitive experiential modality alongside the perceptual modalities (or, alternatively, a plethora of cognitive modalities, perhaps corresponding to cognitive propositional attitudes that can be conscious - judging that $p$, accepting that $p$, suspecting that $p$, conjecturing that $p$, etc.). Underlying this move is the thought that phenomenal intentionality is really a two-faceted phenomenon, in which content is only one facet and another facet is attitude. On this view, attitudes are just as phenomenally manifest as contents, and a conception of phenomenal intentionality which does not take them into account is perforce incomplete (Horgan and Tienson 2002: 522, Kriegel forthcoming §2). I find this the most natural lesson to draw from this 
paper's discussion. However, in a companion piece (Kriegel 2018), I argue against a number of attitude-based approaches to the phenomenal difference between perception and thought.

Obviously, there is one last way forward here, which is to give up on the phenomenal intentionality view, on the grounds that it is unable to account for the phenomenally manifest difference between perception and thought. This seems to me an overreaction, however: I would sooner adopt a primitivist account of the difference than claim that phenomenal character does not ground any kind of intentional directedness. ${ }^{7}$

\section{References}

- Bayne, T. and M. Montague (eds.), Cognitive Phenomenology. Oxford: Oxford University Press.

- Bourget, D. 2017. 'The Role of Consciousness in Grasping and Understanding.' Philosophy and Phenomenological Research 95: 285-318.

- Brentano, F.C. 1874. Psychology from Empirical Standpoint. Edited by O. Kraus. English edition L.L. McAlister. Translated by A.C. Rancurello, D.B. Terrell, and L.L. McAlister. London: Routledge and Kegan Paul, 1973.

- Byrne, A. 2005. 'Consciousness and Nonconceptual Content.' Philosophical Studies 113: 261-274.

- Chudnoff, E. 2015. Cognitive Phenomenology. London: Routledge.

- Dretske, F.I. 1981. Knowledge and the Flow of Information. Oxford: Clarendon.

- Dretske, F.I. 1995. Naturalizing the Mind. Cambridge MA: MIT Press.

- Egan, A. 2006. 'Appearance Properties?' Noûs 40: 495-521.

- Fodor, J.A. 1983. The Modularity of Mind. Cambridge, MA: MIT Press.

- Forbes, G. 2000. 'Objectual Attitudes.' Linguistics and Philosophy 23: 141-183.

- Heck, R.G. 2000. 'Nonconceptual Content and the Space of Reasons.' Philosophical Review 109: 483-523.

- Heck, R.G. 2007. 'Are There Different Kinds of Content?' In J. Cohen and B. McLaughlin (Eds.), Contemporary Debates in the Philosophy of Mind. Oxford: Blackwell.

- Horgan, T. and J. Tienson 2002. 'The Intentionality of Phenomenology and the Phenomenology of Intentionality.' In D.J. Chalmers (ed.), Philosophy of Mind. New York: Oxford University Press.

- Klausen, S.H. 2008. 'The Phenomenology of Propositional Attitudes.' Phenomenology and the Cognitive Sciences 7: 445-462.

- Kriegel, U. 2011. 'The Veil of Abstracta.' Philosophical Issues 21: 245-267.

- Kriegel, U. 2015. The Varieties of Consciousness. New York: Oxford University Press. 
- Kriegel, U. 2018. 'The Perception/Cognition Divide: One More Time, with Feeling.' In C. LimbeckLilienau and F. Stadler (eds.), The Philosophy of Perception and Observation. Berlin and Boston: De Gruyter (2018).

- Kriegel, U. Forthcoming. 'The Three Circles of Consciousness.' in M. Guillot and M. GarciaCarpintero (eds.), The Sense of Mineness. Oxford: Oxford University Press.

- Loar, B. 1987. 'Subjective Intentionality.' Philosophical Topics 15: 89-124.

- Loar, B. 2003. 'Phenomenal Intentionality as the Basis for Mental Content.' In M. Hahn and B. Ramberg (eds.), Reflections and Replies: Essays on the Philosophy of Tyler Burge. Cambridge MA: MIT Press.

- Montague, M. 2007. 'Against Propositionalism.' Noûs 41: 503-518.

- Montague, M. 2017. 'Perception and Cognitive Phenomenology.' Philosophical Studies 174: $2045-$ 2062.

- Phillips, B. Forthcoming. 'The Shifting Border Between Perception and Cognition.' Noûs.

- Pitt, D. 2004. 'The phenomenology of cognition; Or What is it like to think that P?' Philosophy and Phenomenological Research 69: 1-36.

- Rorty, R. 1970. 'Incorrigibility as the Mark of the Mental.' Journal of Philosophy 67: 399-429.

- Shoemaker, S. 1994. 'Phenomenal Character.' Noûs 28: 21-38.

- Siegel, S. 2010. The Content of Visual Experience. Oxford and New York: Oxford University Press.

- Siewert, C. 1998. The Significance of Consciousness. Princeton: Princeton University Press.

- Siewert, C. 2011. 'Phenomenal Thought.' In Bayne and Montague 2011.

- Speaks, J. 2005. 'Is There a Problem about Nonconceptual Content?' Philosophical Review 114: 359398.

- Strawson, G. 1994. Mental Reality. Cambridge MA: MIT Press.

- Strawson, G. 2011. 'Cognitive Phenomenology: Real Life.' In Bayne and Montague (eds.), Cognitive phenomenology. Oxford: Oxford University Press.

- Szabó, Z.G. 2003. 'Believing in Things.' Philosophy and Phenomenological Research 66: 584-611.

- Textor, M. 2007. 'Seeing Something and Believing IN It.' In M.M. McCabe and M. Textor (eds.), Perspectives on Perception. Frankfurt: Ontos.

- Tye, M. 1995. Ten Problems of Consciousness. Cambridge MA: MIT Press.

\footnotetext{
1 A particularly radical version, propounded for instance by Rorty (1967), sees "the mental" as a hodgepodge category that forces together all states that happen to exhibit either phenomenality or intentionality, though these have intrinsically little to do with each other.

${ }^{2}$ On the one hand, 'thinking about' can be used to report a thought of an object, or even a proposition, in a contemplative mode. Thus, when we say 'Jimmy is thinking about the proposition that the weather is nice,' we do not mean to imply that Jimmy takes it to be true that the weather is nice. On the other hand, we can use the 'think about' locution to report a part of a more committal belief-like state. Thus, if Jimmy judges consciously that the weather is
} 
nice, we can say - correctly - that Jimmy is thinking about the weather, or even that he is thinking about the weather being nice.

${ }^{3}$ It might be suggested that if the possibility of representing (sufficiently) high-level properties is admitted to distinguish the faculties of perception and thought, then we could always propose that perceptual experiences are the products of the perceptual faculty whereas thoughts are the products of the faculty of thought. But the problem is that being-producedby-faculty-F does not seem like a phenomenal property, the kind of property that could distinguish perceptual from cognitive phenomenology.

${ }^{4}$ There is a related but more superficial objection, according to which even if the Lyncean creature possesses the concept CHILIAGON, it may not deploy that concept when merely perceiving a chiliagon. To this it could be responded that it is quite hard to refrain from applying a fitting concept one possesses and knows to be fitting (try to see your mother's face not as your mother's face!), and in any case we can stipulate that on occasion the creature fails to refrain from automatically applying the concepts. I think the objector will insist here that even if the creature always applies the concept CHILIAGON as soon as she perceives a chiliagon, the two things are logically separate. But what this means, really, is that the creature could have had the same perceptual experience without applying or even possessing the relevant concepts. Thus the objection we are considering in the main text ultimately underlies the objection just raised. If we can respond to the one, we can respond to the other.

${ }^{5}$ By the way, the worst answer we could give to the question 'What makes it the same mental state, perceptual in both cases, in both worlds?' is 'The phenomenology is the same in both worlds, and is rather a perceptual phenomenology.' For our hope was to use the conceptual/nonconceptual distinction to get underneath the distinction between perceptual and cognitive phenomenology, a gambit that would be frustrated if defending the conceptual/nonconceptual account presupposes a phenomenal difference between perception and cognition.

${ }^{6}$ The plus sign is supposed to denote what accounts for the 'unity of the proposition' - a potential can of worms I am setting aside here.

7 This work was supported by the French National Research Agency's grants ANR-10-IDEX0001-02 PSL and ANR-10-LABX-0087 IEC, as well as by grant 675415 of the European Union's Horizon 2020 Research and Innovation program. For comments on a previous draft, I am grateful to Géraldine Carranante, Ben Phillips, and Enrico Terrone. I have also benefited from presenting the paper at Columbia University, the National University of Singapore, the University of Luxembourg, the University of Milan, and conferences on phenomenal intentionality (Paris, March 2017), perceptual awareness (Paris, July 2017), and perception and observation (Kirchberg, August 2017); I am grateful to the audiences there, in particular Ben Blumson, Davide Bordini, Géraldine Carranante, Marian David, Arnaud Dewalque, Anna 
Giustina, Gabriel Greenberg, Martin Lin, Tricia Magalotti, Olivier Massin, John Morrison, Takuya Niikawa, Elisa Paganini, Mike Pelczar, Jesse Prinz, Susanna Schellenberg, Enrico Terrone, Alfredo Tomasetta, and Nick Young. 